\title{
New Platinum(II) Complex Containing Asymmetric Tetra Dentate Schiff Base Ligand Synthesis, Characterization and DFT Calculation
}

\author{
ALIREZA AKBARI $^{{ }^{*}}$, IRAN SHEIKHSOAEI, LOTFALI SAGHTFOROUSH ${ }^{\S}$, \\ S. YOUSOF EBRAHIMIPOUR ${ }^{\S}$, AND ZOHREH AMIRI ${ }^{\S}$ \\ ${ }^{\S}$ Department of Chemistry, Payame Noor University, 19395-4697, Tehran, I. R. of Iran \\ Department of Chemistry, Shahid Bahonar University, Kerman, Iran \\ a_akbari@pnu.ac.ir
}

Received 20 July 2011; Accepted 5 September 2011

\begin{abstract}
The tetra dentate neutral (E)-4-nitro-2-((2-(2-(pyridin-2-yl) ethylthio) ethylimino) methyl) phenol, (pytaO $\left.{ }_{2} \mathrm{NSalH}\right)$, Schiff-base ligand was synthesized using 1-(2-pyridyl)-3-thia-s-aminopentane (pyta) and 5- $\mathrm{NO}_{2}$ salicylaldehyde. Then the related square planar Pt (II) cationic complex, [Pt (NSNO)] Cl, was synthesized using $\mathrm{PtCl}_{2}\left(\mathrm{SMe}_{2}\right)_{2}$ as precursor complex. The nature of the $\mathrm{pytaO}_{2} \mathrm{NSalH}$ and its platinum complex were determined by the elemental analysis, molar conductivity and spectrochemical (IR, UV-vis, ${ }^{1} \mathrm{HNMR}$ ) techniques. In addition, the fully optimized geometries and vibration frequencies of them together were calculated using the ADF 2009.01 package. Structural parameters are in good agreement with the experimental data. The calculated and experimental results confirmed the suggested structures for the ligand and complex.
\end{abstract}

Keywords: Platinum(II), Schiff base, DFT, ADF.

\section{Introduction}

Chelating ligands containing $\mathrm{N}, \mathrm{S}$ and $\mathrm{O}$ donor atoms show broad biological activity and are of special interest because of the variety of ways in which they are bonded to metal ions. It is known that the existence of metal ions bonded to biologically active compounds may enhance their reactivates ${ }^{1}$. Square planar substitution reaction at $\mathrm{Pt}(\mathrm{II})$ centers have been extensively studied and contributed significantly to current understanding of ligand effects and reactions mechanisms $s^{2,3}$. Platinum is the heaviest member of the group VIII of the transition metals. Interest in the interactions of platinum metals with biologically important molecules began about 35 years ago when Rosenberg, et al. published their discovery that certain platinum complexes exhibit anticancer activity ${ }^{4}$. Cisplatin is the parent compound in this group. It is widely used for the treatment of testicular and ovarian cancers and to a lesser extent head and neck tumors. However, the efficacy of the drug is hampered by severe side effects. The number of platinum complexes that show antitumor activity is still rapidly growing because of attempts to find complexes with greater potency and less toxicity than the existing clinical drugs ${ }^{5-7}$. 


\section{Experimental}

All the chemicals and solvents used for the syntheses were of reagent grade and were obtained commercially from Merck Company. The ligand $\left(\mathrm{PytO}{ }_{2} \mathrm{NsalH}\right)$ and $\mathrm{Pt}\left(\mathrm{SMe}_{2}\right)_{2} \mathrm{Cl}_{2}$ precursor were synthesized and characterized according to our previous published method ${ }^{8,9}$. Reported calculations in this paper were carried out using the Amsterdam density functional (ADF) 2009.01 software $^{10}$. Geometry of the ligand and complex were optimized at DZ basis set except for Pt which TZ basis sets were used. Theoretical calculations of harmonic frequencies at the fully optimized geometries of the ligand and its $\mathrm{Pt}(\mathrm{II})$ complex are performed at B3LYP level ${ }^{11-13}$.

The mentioned complex was prepared by dissolving $\operatorname{Pt}\left(\mathrm{SMe}_{2}\right)_{2} \mathrm{Cl}_{2}(0.0316 \mathrm{~g}, 0.081 \mathrm{mmol})$, in $5 \mathrm{~mL}$ methanol and mixture were stirred for 30 minutes. Separately, $5 \mathrm{~mL}$ triethylamine was added to a solution of pytaNO $\mathrm{S}_{2} \mathrm{salH}$ ligand $(0.0269 \mathrm{~g}, 0.081 \mathrm{mmol})$ and the mixture was refluxed for one hour. The mentioned solution of ligand was added drop-wise to the solution of $\mathrm{Pt}\left(\mathrm{SMe}_{2}\right)_{2} \quad \mathrm{Cl}_{2}$ in nitrogen atmosphere, and stirred for two days. Evaporation of this solution gave an orange precipitate which filtered, washed with ether and dried. (Yield: 45.68\%), FT-IR $\left(\mathrm{KBr}, \mathrm{cm}^{-1}\right): \mathrm{v}=1608(\mathrm{C}-\mathrm{N})_{\mathrm{py}}, 1550(\mathrm{C}=\mathrm{N})_{\mathrm{imi}}, 1321.1(\mathrm{C}-\mathrm{O}), 673.1(\mathrm{C}-\mathrm{S}), 564$, 489; CHN, Cal: C, 34.26; H, 2.88; N, 7.49; Found: C, 32.79; H, 3.50; N, 6.42. M.p. complex $=210^{\circ} \mathrm{C}$ (decomposed).

\section{Results and Discussion}

B3LYP optimized geometries of Ligand (left) and its Pt (II) complex, Figure 1, showed that the metal atom should bonded in a slightly distorted square planar coordination to the oxygen of the phenyl ring, sulfur, iminic and pyridinic nitrogen atoms. As an example, the $\mathrm{C}(1)-\mathrm{O}(1), \mathrm{S}(1)-\mathrm{C}(5)$ and $\mathrm{S}(1)-\mathrm{C}(6)$ bond distances in ligand calculated as $1.353 \AA$, $1.891 \AA$ and $1.89 \AA$ respectively, but changed to $1.316 \AA, 1.87 \AA, 1.86 \AA$ in the complex. In the complex $\left[\mathrm{Pt}\left(\right.\right.$ pytaO $\left.\left._{2} \mathrm{Nsal}\right)\right] \mathrm{Cl}, \mathrm{Pt}-\mathrm{O}(2.101 \mathrm{~A} \square), \mathrm{Pt}-\mathrm{N}(1)(2.101 \mathrm{~A} \square)$ and $\mathrm{Pt}-\mathrm{N}(2)$ (2.186 A $\square$ ) bond lengths slightly longer than related Schiff base complex ${ }^{14-19}$ (Table 1).

Table 1. Comparison of some calculated and reported vibrations.

\begin{tabular}{lcc}
\hline & Reported & Calculated \\
\hline $\mathrm{Pt}-\mathrm{O}$ & $1.976[31] ; 2.005[32] ; 2.006[40]$ & 2.101 \\
$\mathrm{Pt}-\mathrm{N}_{\text {imine }}$ & $1.988[31] ; 1.992[32] ; 2.04[33]$ & 2.101 \\
$\mathrm{Pt}-\mathrm{N}_{\mathrm{py}}$ & $1.940,2.002,2.004[34] ;$ & 2.186 \\
$\mathrm{Pt}-\mathrm{S}$ & $2.279,2.284[36] ; 2.336,2.335,2.337[35]$ & 2.337 \\
$\mathrm{C}(1)-\mathrm{O}$ & $1.314[31]$ & 1.316 \\
$\mathrm{C}(3)-\mathrm{N}(1)$ & $1.316[31]$ & 1.306 \\
\hline
\end{tabular}
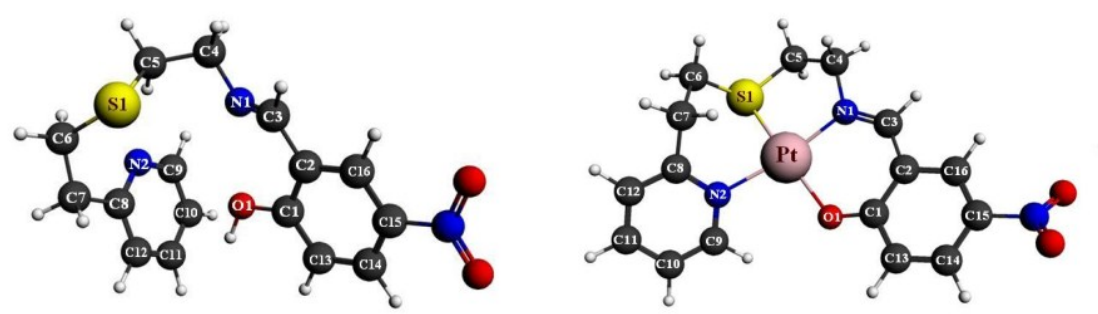

Figure 1. B3LYP optimized geometries of ligand (left) and related Pt (II) complex (right). 
The absorption bands at 3446, 1284.5, 678,1652, $1606 \mathrm{~cm}^{-1}$ in the IR spectrum of ligand are attributed to $v\left(\mathrm{O}-\mathrm{H}_{\text {phenolic }}\right), v\left(\mathrm{C}-\mathrm{O}_{\text {phenolic }}\right), v(\mathrm{C}-\mathrm{S}), v\left(\mathrm{C}=\mathrm{N}_{\text {pyridinic }}\right), v\left(\mathrm{C}=\mathrm{N}_{\text {iminic }}\right)$ respectively. These values are in agreement with similar compounds ${ }^{20}$. Theoretically IR frequencies of ligand and complex are calculated too. The important infrared spectra bands for the synthesized complex and ligand are given in Table 2.

Table 2. The selected experimental and calculated IR vibration frequencies $\left(\mathrm{cm}^{-1}\right)$ of the (pytaO $\mathrm{O}_{2} \mathrm{NsalH}$ ) ligand and its related $\mathrm{Pt}(\mathrm{II})$ complex.

\begin{tabular}{ccccc}
\hline \multicolumn{2}{c}{ Experimental } & \multicolumn{2}{c}{ Calculated } & $\begin{array}{c}\text { Vibration } \\
\text { assignment }\end{array}$ \\
\hline ligand & complex & ligand & complex & \\
- & - & - & 641 & $v(\mathrm{Pt}-\mathrm{O})$ \\
- & - & - & 330 & $v(\mathrm{Pt}-\mathrm{S})$ \\
- & - & - & 489 & $v\left(\mathrm{Pt}-\mathrm{N}_{\mathrm{py}}\right)$ \\
- & - & - & 514 & $v\left(\mathrm{Pt}-\mathrm{N}_{\mathrm{im}}\right)$ \\
678 & 673 & 624 & 607 & $v(\mathrm{C}-\mathrm{S})$ \\
1606 & 1550 & 1661 & 1584 & $(\mathrm{C}=\mathrm{N})_{\mathrm{im}}$ \\
3446 & - & 3328 & - & $v(\mathrm{O}-\mathrm{H})_{\mathrm{ph}}$ \\
\hline
\end{tabular}

These frequencies are observed to be shifted to a lower number after complexation. The C$\mathrm{S}$ bond appears at $670-770 \mathrm{~cm}^{-1}$. We assigned this bond at $678 \mathrm{~cm}^{-1}$ in the ligand and at 673.1 $\mathrm{cm}^{-1}$ in complex theoretically. The observation suggests that the lone pair of the sulfur atom coordinates to platinum and causes the C-S bond shift to lower frequencies in the IR spectrum of complex. The far IR bands in the optimized structure complex show some new bands with medium to weak intensity in $530-425 \mathrm{~cm}^{-1}$ region, assigned to $v(\mathrm{Pt}-\mathrm{N})$ and $v(\mathrm{Pt}-\mathrm{S})$ respectively, which are in agreement with other reported works ${ }^{21}$. The ${ }^{1} \mathrm{H}$ NMR spectra of the ligand and its complex is recorded in DMSO and some data are collected in Table 3.

Table 3. Experimental chemical shifts of ligand and complex in ${ }^{1} \mathrm{H}$ NMR spectra.

\begin{tabular}{cc}
\hline PytaO $_{2} \mathrm{NsalH}_{14.55}(\mathrm{~s}, 1 \mathrm{H}, \mathrm{OH})$ & {$\left[\right.$ PtpytaO $_{2} \mathrm{Nsal}^{+}$} \\
\hline $8.55(\mathrm{~d}, 1 \mathrm{H}$, pyridinic $)$ & - \\
$8.35(\mathrm{~s}, 1 \mathrm{H}$, iminic $)$ & 8.71 \\
$7.65(\mathrm{t}, 1 \mathrm{H}$, pyridinic $)$ & 8.27 \\
$7.19(\mathrm{~m}, 2 \mathrm{H}$, aromatic $)$ & 7.77 \\
$2.83-3.10\left(\mathrm{CH}_{2}\right.$, aliphatic $)$ & 3.37 \\
\hline
\end{tabular}

The observed pick at $14.55 \mathrm{ppm}$ in the ligand spectrum is attributed to the hydroxyl proton. The absences of this proton in the complex confirm the Schiff bases coordination via oxygen of the hydroxyl group too. In all cases, there are down field shifts, which confirm coordination between the metal ion and four mentioned donor sites.

The electronic spectra of the ligand and platinum complex were recorded in methanol solvent at room temperature. The relatively intense absorption at $350 \mathrm{~nm}$ may be assigned to charge transfer. The absorption spectrum of the entire complex is somehow similar to the ligand. This is not surprising since the $\mathrm{d}$-d bands occur as a shoulder on the intense visible band which can be expected to obscure changes in the $\mathrm{d}-\mathrm{d}$ band positions brought about by 
small changes in the environment of the platinum atom. The Low energy band is typical of $\mathrm{d}-\mathrm{d}$ transition in square planar $\mathrm{Pt}(\mathrm{II})$ complexes with the mixed coordination sphere containing nitrogen, oxygen and sulfur atoms ${ }^{8}$.

The absorption band of the ligand at $230-250 \mathrm{~nm}$ is attributed to the benzene $\pi \rightarrow \pi^{*}$ transition. The band around 350-360 nm is due to the $\mathrm{n} \rightarrow \pi^{*}$ transition of the non-bonding electrons presented on the nitrogen of the azomethine group in the Schiff base. In the UVvis. spectrum of the complex, the $n \rightarrow \pi^{*}$ transition band specified to the azomethine group again and is shifted to the higher wavelength indicating the imine nitrogen atom is involved in coordination with the metal ion. The complex of the $\mathrm{Pt}^{+2}$ shows a fewer intense shoulders around $480 \mathrm{~nm}$, which are assigned as d-d transition of the metal ion. The spectrum of the $\mathrm{Pt}^{+2}$ complex shows an intense band at $350 \mathrm{~nm}$, which can be assigned to charge transfer transition of square planar geometry ${ }^{20}$.

Complex and ligand show several intense absorptions in the visible and ultraviolet regions. The absorption in the ultraviolet region is assignable to transitions within the ligand orbitals. Some molecular orbital data of the ligand and its complex are given in Table 4.

Table 4. Percentage composition of the lowest unoccupied and highest occupied molecular orbital (LUMO and HOMO) levels of complex.

\begin{tabular}{|c|c|c|c|c|c|c|}
\hline Orbotal & $\mathrm{E}(\mathrm{ev})$ & $\mathrm{C} \%$ & $\mathrm{~N} \%$ & $\mathrm{O} \%$ & $\mathrm{~S} \%$ & $\mathrm{pt}$ \\
\hline $\mathrm{HOMO}_{-1}$ & -9.712 & $\begin{array}{c}1.03 \mathrm{p}_{\mathrm{x}}+ \\
6.1 \mathrm{p}_{\mathrm{z}}\end{array}$ & $1.37 \mathrm{p}_{\mathrm{z}}$ & $\begin{array}{c}35.43 \mathrm{P}_{\mathrm{x}}+ \\
14.27 \mathrm{P}_{\mathrm{y}}+ \\
28.06 \mathrm{p}_{\mathrm{z}}\end{array}$ & - & $\begin{array}{c}3.72 \mathrm{~d}_{\mathrm{z}}^{2}+ \\
1.68 \mathrm{~d}_{\mathrm{xz}}+ \\
1.05 \mathrm{~d}_{\mathrm{yz}}\end{array}$ \\
\hline HOMO & -9.097 & $\begin{array}{l}1.29 \mathrm{p}_{\mathrm{x}}+ \\
3.38 \mathrm{p}_{\mathrm{y}}^{+} \\
32.76 \mathrm{p}_{\mathrm{z}}\end{array}$ & $4.49 \mathrm{p}_{\mathrm{z}}$ & $\begin{array}{c}17.1 \mathrm{p}_{\mathrm{x}}+ \\
27.9 \mathrm{p}_{\mathrm{z}}\end{array}$ & - & $\begin{array}{c}3.77 \mathrm{~d}_{\mathrm{z}}^{2}+ \\
1.76 \mathrm{~d}_{\mathrm{yz}}\end{array}$ \\
\hline LUMO & -7.308 & $\begin{array}{c}1.01 \mathrm{p}_{\mathrm{y}}+ \\
1.13 \mathrm{p}_{\mathrm{z}}\end{array}$ & $\begin{array}{c}9.64 \mathrm{p}_{\mathrm{x}}+ \\
3.59 \mathrm{p}_{\mathrm{y}}+ \\
5.12 \mathrm{~s}\end{array}$ & $\begin{array}{c}1.04 \mathrm{p}_{\mathrm{x}}+ \\
7.96 \mathrm{p}_{\mathrm{y}}\end{array}$ & $\begin{array}{c}4.99 \mathrm{p}_{\mathrm{x}} \\
+ \\
9.50 \mathrm{p}_{\mathrm{y}}\end{array}$ & $\begin{array}{c}22.55 \mathrm{~d}_{\mathrm{xy}}+ \\
12.06 \mathrm{~d}_{\mathrm{yz}}+ \\
3.93 \mathrm{~d}_{\mathrm{z}}^{2}+ \\
1.60 \mathrm{~d}_{\mathrm{xz}}\end{array}$ \\
\hline $\mathrm{LUMO}_{+1}$ & -6.774 & $\begin{array}{c}1.37 \mathrm{p}_{\mathrm{y}}+ \\
16.05 \mathrm{p}_{\mathrm{x}} \\
+45.14 \mathrm{p}_{\mathrm{z}}\end{array}$ & $\begin{array}{l}7.67 \mathrm{p}_{\mathrm{x}}+ \\
13.58 \mathrm{p}_{\mathrm{z}}\end{array}$ & $3.74 \mathrm{p}_{\mathrm{z}}$ & - & - \\
\hline
\end{tabular}

In the case of the $\left[\mathrm{PtpytaO}_{2} \mathrm{Nsal}\right]^{+}$complex the lowest unoccupied molecular orbital (LUMO) has major contributions from the platinum d orbital's $(40.14 \%)$. The highest occupied molecular orbital (HOMO) is delocalized almost entirely on the ligand and is largely concentrated on the oxygen atom fragment $(45 \%)$. Therefore, the lowest energy absorption near $350 \mathrm{~nm}$ is assignable to a charge- transfer transition taking place from the filled ligand orbital (HOMO) to the vacant $\pi^{*}$ - orbital of the complex (LUMO) ${ }^{40}$, so we can expect the charge transfer is LMCT, not MLCT here.

\section{Conclusion}

The molar conductance value of mentioned complex in methanol, $86.57 \mathrm{ohm}^{-1} \mathrm{~cm}^{2} \mathrm{~mol}^{-1}$, indicate that this complex to be 1:1 electrolyte and thus chloride ion should present outside of the coordination sphere. The electronic spectra of this complex can indicate the square planar geometry, and the obtained values correspond to those reported earlier for the square planar complexes ${ }^{21}$. The down field shifts observed in $\mathrm{H}^{1}$ NMR spectrum of complex, 
comparing the initial ligand, confirmed the coordination between the metal ion and four existing donor sites of the Schiff base. The calculated vibration frequencies are in good agreement with the experimental data. The calculated and experimental results confirmed the suggested structures for the ligand and complex.

\section{Acknowledgment}

This work has been supported by the University of Payame Noor (Iran). We would like to thank the Mashhad branch of Payame Noor University, for further support of this research.

\section{References}

1. Elmali A, Kabak M and Elerman Y, J Mol Struct., 2000, 477, 151.

2. Romeo R, Arena G, Scolaro L M and Plutino M R, Inorg Chim Acta, 1995, 40, 81-92.

3. Eryazici I, Moorefield C N and Newkome G R, Chem Rev., 2008, 108(6), 1834-1895.

4. Rosenberg B, VanCamp L, Trosko J E and Mansour V H, Nature (London), 1969, 222-385.

5. Liu Q, Wang X, Yang X, Liang X and Guo Z, J Inorg Biochem., 2010, 104(11), 1178-1184.

6. Zhu H, Cui K, Wang L and Gou Sh, Bioorg Med Chem Lett., 2005, 15(22), 4936-4943.

7. Bruijnincx P C A and Sadler P J, Advn Inorg Chem., 2009, 61, 1-62.

8. Daneshvar N, Entezami A A, Khandar A A and Saghatforoush L A, Polyhedron, 2003, 22, 1437.

9. Akbari A, Ph D thesis, 2005, Shiraz University, Iran.

10. ADF 2009.01, Scientific computing and modeling center, Virij Universiteit, Amsterdam, The Netherlands, http://www.scm.com.

11. Becke A D, J Chem Phys., 1993, 98, 5648.

12. Becke A D, Phys Rev., 1988, A38, 3098.

13. Lee C, Yang W and Parr R G, Phys Rev., 1988, B37, 785.

14. Kumar A, Agarwal M and Singh A K, Polyhedron, 2008, 27, 485-492.

15. Kumar A, Agarwal M, Singh A and Butcher R J, Inorg Chim Acta, 2009, 62, 3208-3218.

16. Vila J M, TeresaPereira M, Ortigueira J M, Darı'oLata, PezTorres M, Ferna'ndez Ferna ndez A and Adams H, J Organomet Chem., 1998, 566, 93-101.

17. Sengul A, Turk J Chem., 2004, 28, 667-672.

18. Morton M S, Lachi Cotte R J, Vicic D A and Jones W D, Organometallics, 1999, 18, 227- 234.

19. Yassui M, Yoshida S, Kakuma S, Shimamoto S, Matsuma N and Iwasaki F, Bull Chem Soc Jpn., 1996, 69, 2739-2747.

20. Canpolat E and Kaya M, Turk J Chem., 2005. 29, 409-415.

21. Singh R V, Fahmi N and Biyala M K, J Iranian Chem Soc., 2005, 2, 40-46. 


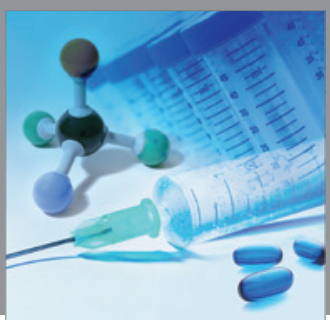

International Journal of

Medicinal Chemistry

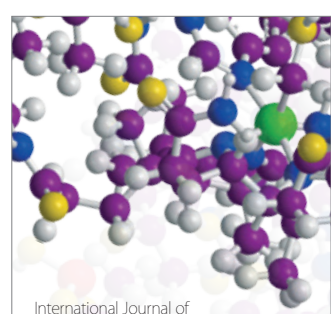

Carbohydrate Chemistry

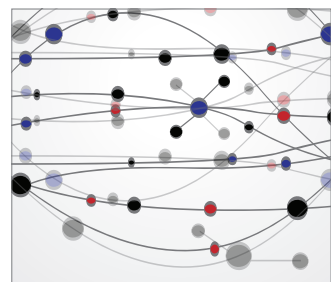

The Scientific World Journal
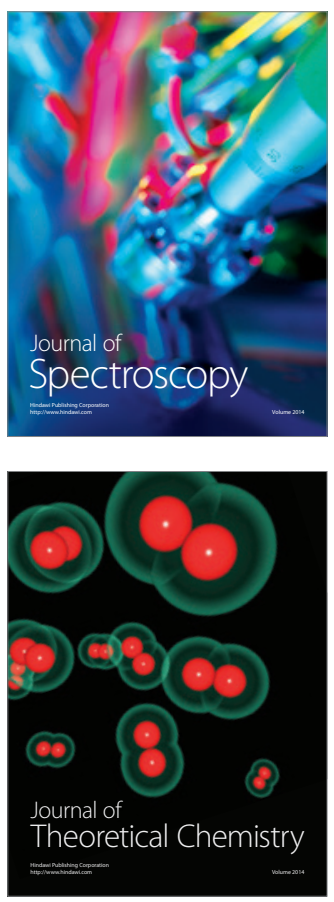
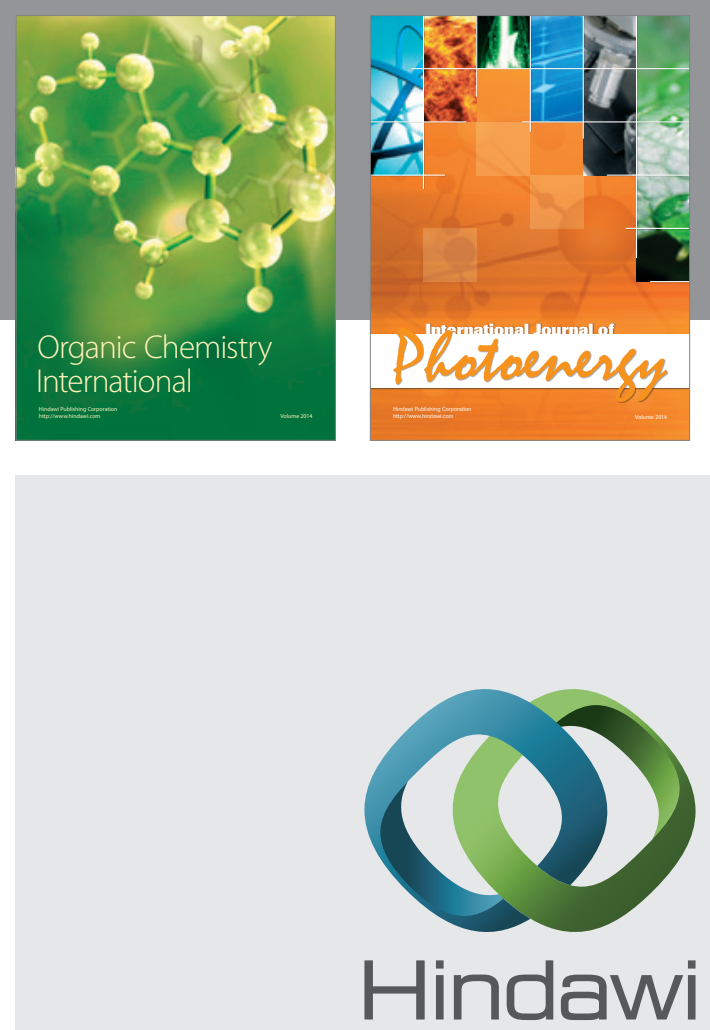

Submit your manuscripts at

http://www.hindawi.com
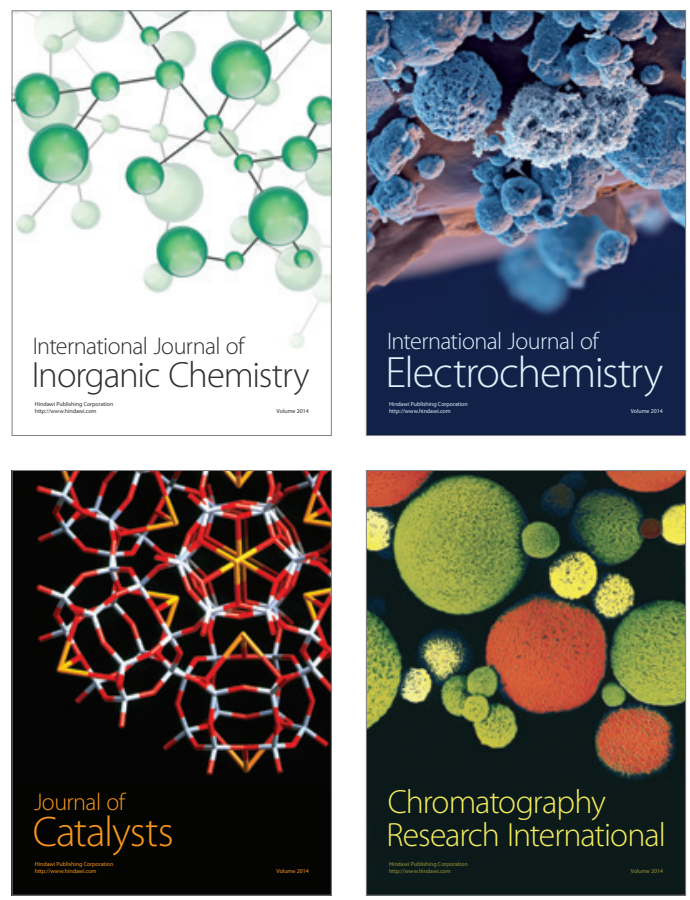
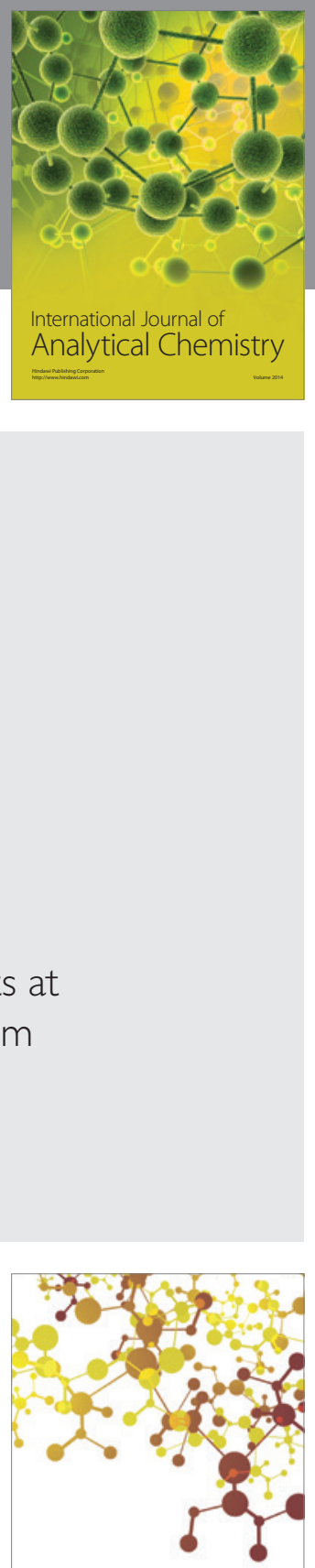

Journal of

Applied Chemistry
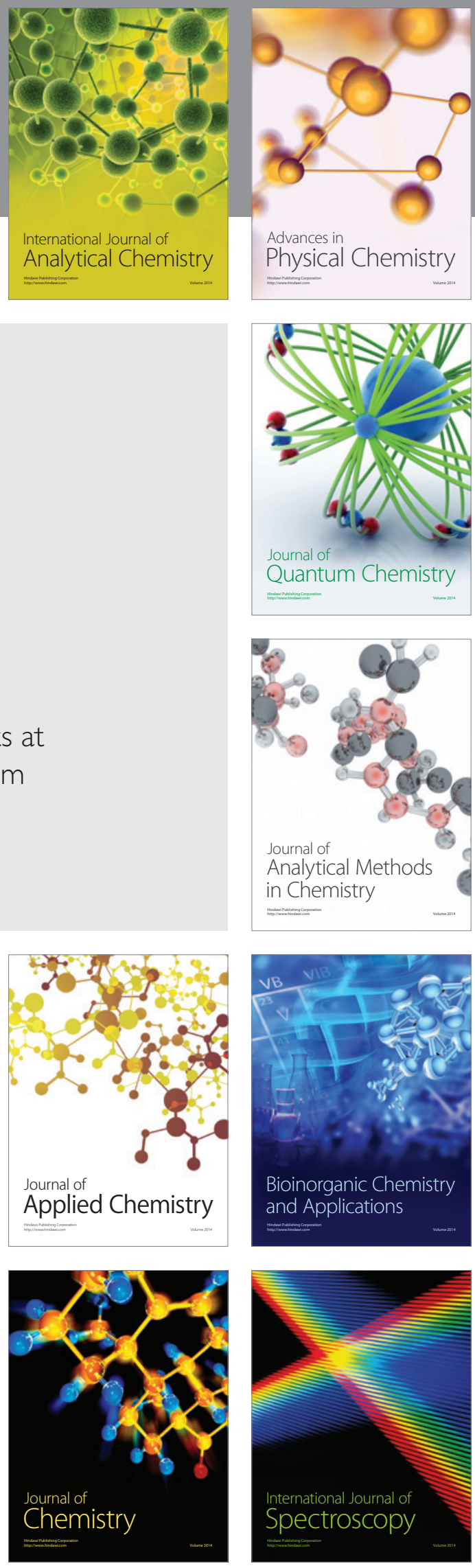